\section{Conformity of pre-gestational weight measurement and agreement of anthropometric data reported by pregnant women and those recorded in prenatal cards, City of Rio de Janeiro, 2007-2008}

\section{Conformidade da aferição de peso no pré-natal e concordância das informações antropométricas referidas pelas gestantes e registradas nos cartões de pré-natal, Município do Rio de Janeiro, 2007-2008}

\section{Roberta Pereira Niquini' \\ Sonia Azevedo Bittencourt" \\ Maria do Carmo Leal" \\ 'Postgraduate Program of Epidemiology in Public Health, Escola Nacional de Saúde Pública Sergio Arouca, Fundação Oswaldo Cruz - Rio de Janeiro (RJ), Brazil. "Departament of Epidemiology and Quantitative Methods in Health, Escola Nacional de Saúde Pública Sergio Arouca, Fundação Oswaldo Cruz - Rio de Janeiro (RJ), Brazil.}

Corresponding author: Roberta Pereira Niquini. Escola Nacional de Saúde Pública Sergio Arouca. Fundação Oswaldo Cruz, Rua Leopoldo Bulhões 1.480, $8^{\circ}$ andar, Manguinhos, CEP: 21041-210,

Rio de Janeiro, RJ, Brazil. E-mail: robertaniquini@ensp.fiocruz.br

Financing source: Fundação Carlos Chagas Filho de Amparo à pesquisa do Estado do Rio de Janeiro - FAPERJ (APQ1 - 170.710/2007), PAPES / FIOCRUZ V (APQ - 403579/2008-2) and the technical department of health of adolescents of the Ministry of Health. Niquini RP was supported by FAPERJ (E-26/100.366/2012; doctoral scholarship).

Conflict of interests: nothing to declare.

\section{Abstract}

Objective: To assess the conformity of the weight measurement process in the pre-gestational care offered in the city of Rio de Janeiro by primary units and hospitals of the National Health System, as well as to verify the agreement between the anthropometric data reported by pregnant women and those recorded in prenatal cards. Method: A cross-sectional study was conducted in 2007 - 2008 with two cluster samples: one to obtain a sample of pregnant women to be interviewed and another one for the weight measurement procedures to be observed. The conformity of the weight measurement process was evaluated according to the Ministry of Health standards, and the agreement between the two sources of anthropometric data was evaluated using mean differences, Bland-Altman method, intraclass correlation coefficient (ICC) and weighted Карpa. Results: Out of the twelve criteria for weight measurement evaluation ( $\mathrm{n}=159$ observations), three weren't in conformity $(<50 \%$ of conformity), two of them only need to be assessed when the scale is mechanical. For the interviewed pregnant women $(n=2,148)$, who had the two sources of anthropometric data, there was a tendency of self-reported height overestimation and pre-gestational and current weight and Body Mass Index underestimation. Accordance between the two sources of anthropometric information, according to ICC and weighted Kappa, were high (> 0.80). Conclusion: Studies may use weight and height information reported by pregnant women, in the absence of prenatal cards records, when it is an important economy to their execution, although the improvement of these two sources of information by means of better anthropometric process is necessary.

Keywords: Anthropometry. Self report. Reproducibility of results. Body Mass Index. Prenatal care. Pregnancy. 


\section{Resumo}

Objetivo: Avaliar a conformidade do processo de pesagem no atendimento pré-natal de unidades básicas e hospitais do Sistema Único de Saúde no Município do Rio de Janeiro, bem como verificar a concordância das informações antropométricas referidas pelas gestantes e registradas nos cartões de pré-natal. Método: Foi conduzido um estudo seccional em 2007 - 2008 para o qual foram realizadas duas amostragens por conglomerado, uma para obter a amostra de gestantes a serem entrevistadas e outra para obter a dos processos de pesagem a serem observados. A conformidade da pesagem foi avaliada segundo normas do Ministério da Saúde e a concordância entre as duas fontes de informação antropométrica foi verificada por meio das médias das diferenças, método de Bland-Altman, coeficiente de correlação intraclasse (CCIC) e Kappa ponderado. Resultados: Dos doze critérios de pesagem ( $\mathrm{n}$ = 159 observações), três revelaram-se não conformes ( $<50 \%$ de conformidade), dois deles necessários apenas em balanças mecânicas. Para as gestantes entrevistadas ( $\mathrm{n}=2.148)$, que tinham as duas fontes de informação antropométrica, observaram-se tendências dos valores referidos superestimarem a estatura e subestimarem o peso e Índice de Massa Corporal pré-gestacionais e atuais. As concordâncias entre as duas fontes de informação, segundo CCIC e Kappa ponderado, foram altas $(>0,80)$. Conclusão: Estudos podem usar informações de peso e estatura referidos pelas gestantes, na ausência de registros nos cartões, quando esta economia for importante para sua execução, embora seja necessário o aprimoramento dessas duas fontes de informação, mediante melhoria do processo antropométrico.

Palavras-chave: Antropometria. Autorrelato. Reprodutibilidade dos testes. Índice de Massa Corporal. Cuidado pré-natal. Gravidez.

\section{Introduction}

The Ministry of Health recommends that prenatal care should involve the questioning on pre-gestational weight and the height measurement in the first appointment, and current weight in all appointments with subsequent calculation of Body Mass Index (BMI), classification of nutritional status, prediction and follow-up of weight gain $^{1}$, which enable the prevention and the treatment of nutritional disorders associated with unfavorable gestational outcomes $^{2,3}$. When these data are registered in the medical record and card of the pregnant women, it is possible to make information available for the follow-up of the nutritional status by professionals of different health services and for studies that can contribute in the formulation of health and nutrition policies ${ }^{1,4}$.

The medical record stands out as the main source of information to analyze the process of care ${ }^{5}$, but since it is incomplete ${ }^{6,7}$, it is usually necessary to supplement it with other sources, such as interviews with the users ${ }^{5}$.

Tendencies of overestimation of height and underestimation of referred weight and BMI have been observed, even though the level ranges according to characteristics of the population ${ }^{8,9}$, besides flaws in the process of weight measurement among users of the Unified Health System (SUS - Sistema Único de Saúde) $)^{10,11}$, which can compromise not only the registers of anthropometric measures, but also the values reported by the users. It is worth to mention that, despite the broad demand for nutritional care among pregnant women assisted at SUS ${ }^{12}$, little is known about the conformity of its weighing process.

Therefore, this study aimed at assessing the conformity of the weighing process in the prenatal care of Basic Health Units (UBS - Unidades Básicas de Saúde) and hospitals of SUS in the city of Rio de Janeiro, according to the recommendations of the Ministry of Health, as well as to verify the agreement between the anthropometric 
data referred by the pregnant women and those registered in their prenatal cards.

\section{Methods}

This is a subproject inserted in the interinstitutional study "Avaliação da qualidade da assistência pré-natal na rede SUS do Município do Rio de Janeiro" (Assessmenf of prenatal care in SUS in the city of Rio de Janeiro), conducted by the research group "Saúde da Mulher, da Criança e do Adolescente - Determinante Sociais, Epidemiologia e Avaliação de Políticas, Programas e Serviços" (Health of the Women, Child and Adolescent Social Determinants, Epidemiology, and Assessment of Policies, Programs and Services). For that, two cluster samples were performed in two stages: one to obtain the sample of weight measurement processes to be observed and the other one to obtain the sample of pregnant women to be interviewed.

For both sampling plans, the first stage selected the health establishments with low-risk prenatal care in the SUS network of the city of Rio de Janeiro, and places with high rates of violence (5\%) and monthly average of prenatal appointments lower than $80(19 \%)$ were excluded, according to data from the Municipal Health Secretariat of Rio de Janeiro (SMS-RJ) for the first semester of 2005.

These primary selection units were stratified into UBS and hospitals. Inside these strata, there was a simple random selection by programmatic area (territorial and administrative division adopted by SMS-RJ), and the number of units selected in each programmatic area was proportional to the number of existing ones. Out of all of the units that met the selection criteria, $40 \%$ of the hospitals ( $n=5)$ and UBS ( $n=26)$ were selected, and such percentage was not higher in order to make the logistics of data collection feasible, given the calculated sample size and existing resources.

In the second sampling stage of weight measurement processes, one shift of prenatal care was randomly selected in each one of the 31 health units of the sample. In each selected shift, the weight measurement process of the five first pregnant women who were weighed was observed, at the presence of a health professional in charge of weight measurement; of the first four pregnant women weighed by each professional, at the presence of two professionals in charge; and of the three pregnant women weighed by each professional, when there were three professionals in charge. The sample calculation of the weighing observations was established by considering a 5\% significance level, $50 \%$ percentage, $9.7 \%$ margin of error and design effect of 1.5, accounting for 155 observations.

In the second sampling stage of pregnant women to be interviewed, they were selected according to days of the week and work shifts, systematically, according to the order of exit of prenatal appointments with the doctor or nurse, until fulfilling the sample predicted for each health unit. In order to obtain the interval for the systematic sampling, when the interviewers arrived to the units they checked the number of pregnant women, at any gestational age, which would be assisted in the shift, and divided it by six (maximum number of interviewees per shift).

After prenatal appointments, the selected pregnant women were invited to participate in the research (stages of interview and photocopy of the prenatal card); those who refused to participate were asked to answer about age and schooling. In order to test if the pregnant women who refused to participate in the study and the ones who participated showed differences with regard to these characteristics, the non-parametric Mann-Whitney test was used. These refusals (6.6\%) were replaced in the sample.

The size of the sample of pregnant women to be interviewed was established according to the parameters: $5 \%$ significance level, $50 \%$ proportion and $2.5 \%$ margin of error. The correction was made for finite population (25,208 prenatal appointments/month) and 
design effect (1.5), accounting for the sample of 2,187 pregnant women. Sample allocation was proportional to the monthly average of prenatal appointments in the first semester of 2005 in each stratum, being $63 \%$ for UBS, $35 \%$ for hospitals and $2 \%$ for labor homes, and the sample size of each stratum was divided by the number of sample units per stratum, accounting for 53 interviews in each UBS, 153 per hospital and 44 for the labor home. Even though the labor home (only one in the city) was considered as a stratum for sample planning, it was excluded from the analysis for the inclusion of the design effect, thus obtaining a sample of 2,148 pregnant women.

For the conduction of statistical analyses, each element of the samples was pondered by the inverse of its selection probability, and a calibration to restitute the known distribution of prenatal appointments.

The instruments used to interview pregnant women and to directly observe the weighing process were tested in a pilot study, and the field team in charge of its application was comprised of 6 supervisors and 36 trained interviewers. Data collection took place from November 2007 to 2008. Questionnaires went through three revision steps and double typing in the Access software.

The instruments of direct observation used to assess the conformity of the weight measurement process of pregnant women was built based on the procedures described in Food and Nutritional Surveillance Guide of Sisvan ${ }^{13}$ and in the Prenatal and Postpartum Guide of the Ministry of Health ${ }^{1}$. These were adopted as conformity patterns assessed by twelve criteria, divided into four evaluation blocks: (1) Conditions of scale and environment before weight measurement (criteria: environment in which the flow of people is not detrimental to the execution of the process, locked scale and calibrated/zero scale); (2) Preparation of the pregnant women for weight measurement (criteria: barefoot pregnant woman, with light clothes and at the center of the scale); (3) Weight reading (criteria: reading facing the scale, when the needle of the scale beam was aligned with the wheel, reading and registration with the locked scale and with the woman on the scale); (4) Place of weight registration (criteria: in the medical record and card of the woman).

The weight measurement criteria were classified as: high conformity (conformity $\geq 90 \%$ ), in partial and acceptable conformity ( $\geq 70 \%$ and $<90 \%$ ), partial and non-acceptable conformity ( $\geq 50 \%$ and $<70 \%$ ) and not in conformity $(<50 \%)$, according to the cutoff points used by Dubeux et al. ${ }^{14}$. The absolute and relative frequencies of units with scales that had records of preventive maintenance were presented, even as of the places in which the scales were located.

In the same occasion when the instrument of interview was applied with the pregnant women, which obtained selfreported values of height, pre-gestational and current weight, sociodemographic and prenatal care information, the photocopies of the prenatal cards of the women were obtained, and from there it was possible to extract anthropometric and prenatal care data.

The interviewed pregnant women were separated into two groups: of the ones who knew how to report height, pre-gestational and current weight measurements, and the ones who did not know how to report at least one of these anthropometric measurements. For the comparison between groups, means and standard deviations (SD) of age, schooling years, gestational age at the date of the interview, number of prenatal appointments and weight registers in the card were presented, as well as the relative frequency of pregnant women with height, pre-gestational and current weight registers in the prenatal card. It was tested whether pregnant women who knew how to report the three measurements showed significant differences $(\mathrm{p}<0.05)$ in relation to the others as to these variables, by means of the non-parametric Mann-Whitney test, for continuous variables, and Pearson's chi-squared test, for categorical variables.

In order to evaluate the agreement of anthropometric data, means and SD of the measurements reported by the pregnant women and registered in prenatal cards were 
presented, as well as the differences between the two sources of information, besides agreement limits (mean of differences $\pm 1,96 \mathrm{SD}$ ). The agreement between the reported and registered height, pre-gestational and current measurements was also assessed by Bland-Altman graphs ${ }^{15,16}$.

In order to obtain a concise agreement measurement of the anthropometric data reported by the pregnant women and registered in the cards, the Intraclass Coefficient Correlation (ICC) was calculated ${ }^{17}$.

The agreement between BMI categories (low weight, eutrophy, overweight and obesity) was also analyzed, obtained through reported and registered information by means of the weighted Kappa (Kp) statistical calculation, with linear reduction weights. Pre-gestational nutritional status was classified according to the criteria of BMI percentile classification in relation to age and gender of the reference standard National Health and Nutrition Examination Survey II for adolescent pregnant women, and the BMI classification for people aged 20 years or more of the WHO for adult pregnant women ${ }^{18}$. The current nutritional status was classified based on the BMI table per gestational week by Atalah et al. ${ }^{19}$, which, despite its acknowledge limitations ${ }^{20,21}$, is currently recommended by the Ministry of Health ${ }^{1,13}$.

Data agreement was classified, according to Landis and $\mathrm{Koch}^{22}$, in: poor $(<0)$, mild $(0-$ $0.2)$, weak $(0.21-0.4)$, moderate $(0.41-0.60)$, substantial $(0.61-0.80)$ and almost perfect $(0.81-1)$. Analyses were performed in the $\mathrm{R}$ software, version 2.14.0.

The research was approved by the Research Ethics Committees of Escola Nacional de Saúe Pública Sergio Arouca/FIOCRUZ (Report n. 142/06) and SMS-RJ (Report n. 145 A/2007). There is no conflict of interest in relation to the methods used as part of the investigation or financial interest of the researchers.

\section{Results}

In $71.0 \%(n=22)$ of the 31 assessed health units, the scale was located in the weighing or screening room; in $25.8 \%(\mathrm{n}=8)$, in the obstetrician or the nurse's room; and in $3.2 \%(\mathrm{n}=1)$, in a place with no privacy. Among the health units, $6.4 \%(n=2)$ had registers of preventive maintenance of the scales. In 1 unit, there were 3 professionals in charge of weight measurement; in 2 units, there were 2 professionals in charge; and in 28 units, there was 1 professional in charge, and in 3 of these only 3 observations were made (number of pregnant women weighed in the selected shift), so the final sample was constituted of 159 observations of the weight measurement process.

As to the conformity of the weight measurement process, presented in Table 1 , it is observed that block (2) was the one with best performance, with two high conformity criteria (barefoot pregnant woman; at the center of the scale) and one with partial and acceptable conformity (pregnant woman wearing light clothes). Each one of the three other blocks presented one criterion with partial and acceptable conformity.

Out of all of the criteria, three were considered with partial and unacceptable conformity, and three others with no conformity (blocked scale before weight measurement; reading and registration of the weight with the blocked scale; weight registration in the pregnant woman's card), and two of them were necessary only when measuring weight in mechanical scales (Table 1).

The pregnant women who accepted to participate in the study and were interviewed $(\mathrm{n}=2,148)$ were no different from those who refused to participate $(n=142)$ as to age and schooling, according to the non-parametric Mann-Whitney test, with $5 \%$ significance level.

Interviewees were aged 24.8 years old, in average, with 8.4 schooling years, 26.7 weeks of pregnancy, 4.5 appointments and 3.7 weight records in the card (Table 2). Height, pre-gestational and current weight registers were found in 30.6, 25.8 and $96.6 \%$ of the prenatal cards, respectively, and the percentage of pregnant women who knew how to report these measurements was of 71.2, 91.9 and $97.9 \%$, respectively, therefore, 
Table 1 - Weight measurement process conformity in prenatal care offered by primary health units and hospitals of National Health System in the City of Rio de Janeiro.

Tabela 1 - Conformidade do processo de aferição do peso no pré-natal de unidades básicas de saúde e hospitais do Sistema Único de Saúde no Município do Rio de Janeiro.

\begin{tabular}{llc}
\hline Criteria & $\%$ & Total \\
\hline Block 1 - Conditions of the scale and environment before weight measurement & & 159 \\
\hline Environment without flow of people that can harm the execution of the process & 87.8 & 132 \\
Blocked scale* & 40.3 & 159 \\
Calibrated/zero scale & 51.2 & 159 \\
\hline Block 2 - Preparation of the pregnant woman for weight measurement & 97.3 & 159 \\
\hline Barefoot & 83.6 & 159 \\
With light clothes & 94.2 & 159 \\
At the center of the scale & & 132 \\
\hline Block 3 - Weight reading & 69.1 & 132 \\
\hline Facing the scale & 80.6 & 159 \\
When the needle of the scale beam is aligned with the wheel* & 39.6 & 159 \\
Reading and registration of weight with blocked scale* & 63.8 & 159 \\
\hline Reading and registration of weight with the pregnant woman on the scale & & 85.1 \\
\hline Block 4 - Place of weight registration & 39.5 & \\
\hline Medical record & & \\
\hline
\end{tabular}

*Only evaluated in weight measurement in mechanical scales $(n=132)$.

*Avaliado apenas em aferições de peso em balanças mecânicas $(n=132)$

Table 2 - Prenatal care and socio-demographic characteristics of interviewed pregnant women, who knew the three anthropometric measures (height, pre-gestational and current weight) and who did not know at least one and differences tests between the two groups.

Tabela 2 - Características sociodemográficas e do pré-natal de gestantes entrevistadas, que souberam referir as três medidas antropométricas (estatura, peso pré-gestacional e atual) e que não souberam referir pelo menos uma e testes de diferenças entre os dois grupos.

\begin{tabular}{lcccr}
\hline Variables & $\begin{array}{c}\text { Total } \\
(\mathrm{n}=2,148)\end{array}$ & $\begin{array}{c}\text { Reported the three anthro- } \\
\text { pometric measurements } \\
(\mathrm{n}=1,434)\end{array}$ & $\begin{array}{c}\text { Did not report at } \\
\text { least one } \\
(\mathrm{n}=714)\end{array}$ & $\mathrm{p}$-value \\
\hline Age in years [Mean (SD)] & $24.8(6.4)$ & $25.0(6.1)$ & $24.3(6.9)$ & $0.001^{*}$ \\
Schooling years [Mean (SD)] & $8.4(2.8)$ & $9.00(2.6)$ & $7.3(2.8)$ & $<0.001^{*}$ \\
Gestational age at the interview [Mean (SD)] & $26.7(8.7)$ & $26.7(8.7)$ & $26.7(8.7)$ & $0.890^{*}$ \\
Number of prenatal appointments [Mean (SD)] & $4.5(8.2)$ & $4.7(8.6)$ & $4.2(7.2)$ & $0.004^{*}$ \\
Number of weight register in the card [Mean (SD)] & $3.7(2.2)$ & $3.9(2.3)$ & $3.5(2.1)$ & $0.004^{*}$ \\
Height registers in the card (\%) & 30.6 & 37.1 & 17.5 & $<0.001^{* *}$ \\
Pre-gestational weight in the card (\%) & 25.8 & 29.3 & 18.9 & $<0.001^{* *}$ \\
Current weight register in the card (\%) & 96.6 & 96.7 & 96.4 & $0.885^{* *}$ \\
\hline
\end{tabular}

*Mann-Whitney test; **Pearson's Chi-square test.

*Teste de Mann-Whitney; ${ }^{* *}$ Teste de qui-quadrado de Pearson. 
$66.8 \%(\mathrm{n}=1,434)$ reported the three anthropometric measurements.

Pregnant women who did not know how to report at least one of the anthropometric measurements were significantly $(5 \%$ level) younger, with lower schooling and less prenatal appointments, as well as anthropometric measurements in their cards (Table 2).

As it can be observed in Table 3, the mean of differences between the data reported by the pregnant women and those registered in prenatal cards was positive for height, revealing a tendency of overestimation of reported values, and negative for pre-gestational and current weight and BMI, with tendencies to underestimate the reported values.

In the Bland-Altman graphs presented for height, current and pre-gestational measurements (Figure 1), there is agreement between the measurements reported by the pregnant women and those registered in the cards (points close to the horizontal line of difference equals zero).

However, concerning height measure ment (Figure 1A), a larger concentration of points is verified above the line of difference equals to zero and the upper limit of agreement. The estimated regression line (dotted line) presents a slight inclination (angular coefficient $=0.03$ ), which, due to its magnitude, was not seen as an important proportional bias. Since the straight line is almost parallel to the $\mathrm{x}$ axis and is about 0.012 meters above the line of difference equals to zero, it reveals a fixed measurement bias, corroborating the tendency of overestimating reported height, when compared to the registered one. The $95 \%$ concordance limits also prove this tendency (from -0.053 to $0.077 \mathrm{~m}$ ), which include a $93.5 \%$ of the differences. Such limits do not reveal compromising magnitude errors for the use of reported height measurement in scientific research (Table 3).

As to current and pre-gestational weight measurements, a larger concentration of points below the line of difference equals to zero and the lower concordance limit was observed. For current weight (Figure $1 B)$, the estimated regression line is practically parallel to the $\mathrm{x}$ axis (angular coefficient $=-0.004)$, and is about $0.270 \mathrm{~kg}$ below the line of difference equals to zero, revealing a fixed bias, which confirms the tendency to underestimate the reported weight values. The $95 \%$ concordance limits (from -3.541 to $3.001 \mathrm{~kg}$ ), which comprise $96.9 \%$ of the differences, also corroborate this tendency and do not reveal compromising errors to the use of the current reported weight in studies (Table 3).

Table 3 - Number of pregnant women with reported and recorded anthropometric information and central tendency, dispersion and agreements measures of those two sources of information.

Tabela 3 - Número de gestantes com informações antropométricas referidas e registradas e medidas de tendência central, dispersão e concordância dessas duas fontes de informação.

\begin{tabular}{|c|c|c|c|c|c|c|c|}
\hline \multirow{2}{*}{ Variables } & \multirow{2}{*}{$\begin{array}{l}\text { Pregnant women } \\
\text { with both sources of } \\
\text { information } \\
n(\%)\end{array}$} & \multirow{2}{*}{$\begin{array}{c}\begin{array}{c}\text { Reported } \\
\text { measurement }\end{array} \\
\text { Mean (SD) }\end{array}$} & \multirow{2}{*}{$\begin{array}{c}\text { Registered } \\
\text { measurement } \\
\text { Mean (SD) }\end{array}$} & \multicolumn{2}{|c|}{ Difference (Rep - Reg) } & \multirow{2}{*}{$\operatorname{ICC}(95 \% \mathrm{CI})$} & \multirow{2}{*}{$\mathrm{Kp}$} \\
\hline & & & & Mean (SD) & $95 \% C L$ & & \\
\hline Height (m) & $627(29.2)$ & $1.605(0.068)$ & $1.594(0.066)$ & $0.012(0.033)$ & $-0.053-0.077$ & $0.867(0.829-0.902)$ & - \\
\hline Pre-gestational weight $(\mathrm{kg})$ & $512(23.8)$ & $61.010(13.881)$ & $61.295(13.61)$ & $-0.285(3.820)$ & $-7.772-7.202$ & $0.961(0.943-0.975)$ & - \\
\hline Current weight (kg) & $2.046(95.2)$ & $69.926(14.800)$ & $70.196(14.857)$ & $-0.270(1.669)$ & $-3.541-3.001$ & $0.994(0.991-0.996)$ & - \\
\hline Pre-gestational BMI $\left(\mathrm{kg} / \mathrm{m}^{2}\right)$ & $273(12.7)$ & $23.725(4.923)$ & $24.135(4.938)$ & $-0.410(1.675)$ & $-3.693-2.873$ & $0.939(0.908-0.962)$ & 0.81 \\
\hline Current BMI (kg/m²) & $604(28.1)$ & $27.473(5.423)$ & $27.911(5.452)$ & $-0.437(1.235)$ & $-2.858-1.984$ & $0.971(0.962-0.979)$ & 0.89 \\
\hline
\end{tabular}

SD: standard deviation; Rep - Reg: Reported measurement - Registered measurement; CL: concordance limit; ICC: intraclass correlation coefficient; $95 \%$ CI: 95\% confidence interval; Kp: Weighted Kappa.

SD: desvio padrão; Rep - Reg: medida referida-medida registrada; CL: limite de concordância; ICC: Coeficiente de Correlação Intraclasse; $95 \%$ Cl: Intervalo de confiança de 95\%; Kp: Kappa ponderado. 
As to pre-gestational weight (Figure 1C), the estimated regression line also presents slight inclination (angular coefficient $=0.02$ ), being located below the line of difference equals to zero for mean weights $\leq 60 \mathrm{~kg}$ and above the line in the interval $>80 \mathrm{~kg}$ (where $8.4 \%$ of the observations are located). Such inclination is explained by the fact that, in this last weight interval, there are less observations and the presence of two outliers (with differences $\geq 20 \mathrm{~kg}$ ). By excluding these two outliers (Figure 1D), the regression line is practically parallel to the $\mathrm{x}$ axis (angular coefficient $=0.0005$ ) and about $0.38 \mathrm{~kg}$ (mean of differences after the exclusion of the outliers) below the line of difference equals to zero, which reveals a fixed bias and confirms the tendency to underestimate the reported pre-gestational values. The 95\% concordance limits (from $-7,772$ to $7.202 \mathrm{~kg}$ ) corroborate this tendency to underestimate the reported pre-gestational weight measurements and revealed the presence of more expressive differences between measurements (Table 3).

Almost perfect concordances between the anthropometric measurements reported by pregnant women and those registered in prenatal cards were revealed by the ICC values obtained for height (0.867), pre-gestational weight (0.961) and current weight (0.994), pre-gestational BMI (0.939) and current BMI (0.971) (Table 3).

As to pre-gestational BMI classification ( $n=273$ ), considering the registers in the prenatal card as reference, it was observed that, among the pregnant women who were classified with low weight $(\mathrm{n}=16)$, $87.5 \%$ of them remained in this category based on the reported information. Such perfect concordance of pre-gestational BMI categories was observed for $93.1 \%$ of the pregnant women classified as eutrophic ( $n=160$ ), for $74.3 \%$ of those classified with overweight $(\mathrm{n}=70)$ and $85.2 \%$ of the obese ones $(n=27)$. It is important to mention that, based on the reported values, $12.5 \%$ of the pregnant women with low weight, $21.4 \%$ of those with overweight and $3.7 \%$ of the obese would have been classified as eutrophic.

With relation to current BMI $(\mathrm{n}=604)$, also assuming the registers of the prenatal card as reference, the agreement between BMI categories was perfect for $93.6 \%$ of the pregnant women with low weight $(n=94)$,
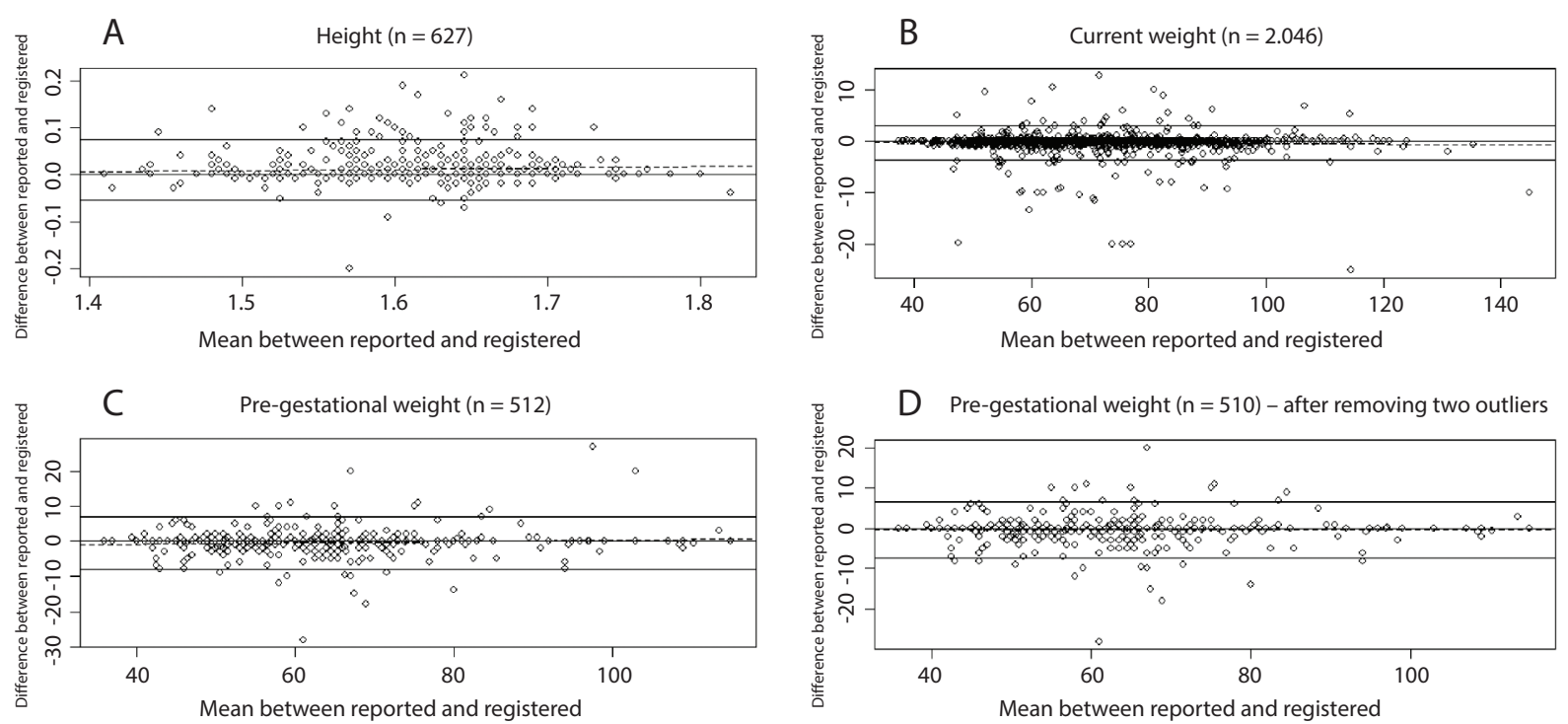

Figure 1 - Differences between measures of height, current and pre-gestational weight referred by pregnant women and recorded on the prenatal card, according averages of the measures.

Figura 1 - Diferenças entre medidas de estatura, peso atual e pré-gestacional referidas pelas gestantes e registradas no cartão de pré-natal, segundo médias das respectivas medidas. 
$86.7 \%$ of the eutrophic ones $(n=233)$, $88.5 \%$ of those with overweight $(\mathrm{n}=156)$ and $86.8 \%$ of the obese $(n=121)$. Based on the reported values, $6.4 \%$ of those with low weight and $9.6 \%$ of the ones with overweight would have been classified as eutrophic.

The weighted Kappa value for pre-gestational and current BMI categories was 0.81 and 0.89 , respectively (Table 3 ).

\section{Discussion}

Weight measurement was performed in a proper room in little less than three quarters of the assessed units, and the greatest lack of adaptation was observed in the unit where the process was conducted in the corridor, with no privacy, which causes the pregnant women not to wear light clothes at the time of weighing. This fact damages the validity of the measurement. The lack of maintenance of the scales is a factor of concern, which was observed in almost of all the health units. This can result in the use of equipment with poor conservation (with difficulties to handle the calibrator, rusty points, among others), which can lead to errors and damage the accuracy and validity of measurements, besides affecting the useful life of the equipment ${ }^{10,13}$. These issues were also observed in studies that assessed the weight measurement process in children ${ }^{10,11}$.

Out of the three assessment criteria of the weight measurement process which are not in conformity in the study, two only need to be performed when the scale is mechanical. Therefore, attitudes to increase this conformity include not only the periodical maintenance of the equipment and the training of the professionals in charge of weight measurement, but also the replacement of mechanical scales with electronic ones, which are easier and more practical to be used ${ }^{10}$. Such initiatives would increase the reliability of the measured weight values and those registered in medical records and prenatal cards, thus enabling the proper diagnosis of nutritional disorders and the broad use of these data in studies $^{1,4}$.

Two articles published in the past ten years with the objective of assessing the measured weight of children aged between 2 and 5 years old in a platform scale, assisted in units of SUS in the city of Rio de Janeiro $(\mathrm{n}=87 \text { children })^{10}$ and in cities of the State of Alagoas $(n=134 \text { children })^{11}$, observed even worse conformity than the one found in this study for the following criteria: calibrating the scale ( 10.3 and $0 \%$, respectively) and reading the weight when the needle of the balance beam was aligned with the wheel (37.9 and 58.4\%, respectively), and the difference in the last criterion could possibly be explained by the difficulty of the child to stay still on the scale in comparison to the pregnant woman. However, they found better conformity for the criterion reading the weight facing the scale (100 and 90.3\%, respectively), which may have occurred due to the closest attention and proximity that the child requires from the professional during weight measurement.

The high conformity for the criterion of placing the user in the center of the scale at the time of weighing ${ }^{10}$ and the superior percentage of conformity of the weight registered in the medical record when compared to the percentage found in the card registration ${ }^{11}$ were also observed by these authors. However, due to the high percentage of current weight registers in prenatal cards $(96.6 \%)$, it is possible that, in the prenatal care routine, the responsibility of passing the measured weight value from the records to the cards is considered to be an activity of the health professional who performs prenatal care, and not of the one who measures the weight.

As to the interviewed pregnant women, the group that did not know how to report at least one of the anthropometric measurements was constituted of pregnant women who least attended prenatal care and had more social vulnerability, as described by Oliveira et al. ${ }^{23}$, which reveals the need of this group for more attention in prenatal care. 
Corroborating the findings in this study, Engstrom et al. ${ }^{9}$, by reviewing the articles published in English from 1970 and 2002 presenting the mean of current height and weight differences between measured and reported data, also found reduced mean differences between the two sources of information, with tendency to overestimate reported height and underestimate reported weight and BMI. The authors emphasized that even though the mean difference had relatively small magnitude for adults, the SD of the differences is big, which suggests the high level of dispersion of differences around the mean, calling the attention for the presence of expressive errors in the reported values, which was also observed in this study for the pre-gestational measurement.

The mean of differences of the two sources of height information found in this study was very close to the ones observed by Fonseca et al. ${ }^{24}$ among women aged 22 to 70 years old, employees of a university (0.011; $\mathrm{SD}=0.030$ ), and by Oliveira et al..$^{23}$, among pregnant women who were admitted in two State hospitals located in the city of Rio de Janeiro because of labor (0.012), and these studies compared the reported and the measured height value.

For current reported and measured weight measurements, Oliveira et al. ${ }^{23}$ found a mean difference 1.9 times higher, and Fonseca et al. ${ }^{24}, 4.2$ times higher than the one observed in this study. As to current BMI, the mean difference was 1.8 times higher in the study by Fonseca et al. ${ }^{24}$. These discrepancies can be explained by the time passed between weight measurement and reported measurement. While in this study pregnant women were interviewed right after the prenatal appointment, in which one of the procedures is weight measurement, in the one by Oliveira et al. ${ }^{23}$ weighing was performed in pre-partum and the interview, in the post-partum; in the one by Fonseca et al. ${ }^{24}$, the interview with the employees, who may not have had their weight measured recently, was conducted in a period prior to weighing.
As to the pre-gestational weight reported by pregnant women and the one registered in the card, Oliveira et al. ${ }^{23}$ found a mean difference 9.5 times higher than the one observed in this study, possibly because they interviewed the women in the postpartum instead of during gestation, which may have increased memory bias.

At assessing the concordance between the reported and measured anthropometric measurements, by means of the Bland-Altman method ${ }^{15,16}$, other authors have observed good concordance, also with tendencies to overestimate reported height ${ }^{23,24}$ and underestimate reported current weight $^{23-25}$. As to pre-gestational weight, Oliveira et al. ${ }^{23}$ verified higher tendencies to underestimate the reported value in relation to the one registered in the card, possibly due to the aforementioned reason.

As to the concordance between reported pre-gestational data and that registered in the card, as well as reported and measured weight, Oliveira et al. ${ }^{23}$, even though having observed inferior ICC values in comparison to this study, also found almost perfect concordances. As to the concordance of reported and measured height measurements, besides being inferior to the ones in this study, it was classified as substantial ${ }^{23}$. Other authors also verified, in different populations (workers of both genders), by calculating the ICC, almost perfect concordances between reported and measured height ${ }^{24}$, current weight $^{24,25}$ and current $\mathrm{BMI}^{25}$.

Among the hypotheses for the higher concordance observed in this study concerning current weight and height measurements in comparison to the ones of Oliveira et al. ${ }^{23}$, there is the reproduction of measurement errors made by professionals in the units in the information reported by the pregnant women. It is important to stand out some limitations of this study: the fact that there was no assessment of the state of conservation of the scales and anthropometers of the units, as well as the conformity of the height measurement process; the non-repetition of measurements by researchers trained in gold-standard 
equipment, which did not enable the assessment of measurement validity.

The fact that the worse concordance between reported and registered anthropometric measurements, according to ICC, was observed for height leads to the question that, while weight measurement is recommended in all prenatal appointments, the height measurement is only predicted for the first appointment of adult pregnant women, and trimonthly for pregnant teenagers ${ }^{1}$, which means that this measurement is much less frequent, with registers in about one third of the prenatal cards of the interviewed pregnant women. The expressive amplitude of the concordance limit of the differences between pre-gestational weight measurements calls the attention for the guideline of the Ministry of Health, which establishes that the pre-gestational weight registered in the card can be the reported one, or the measured one until the $13^{\text {th }}$ week of pregnancy, so that professionals can choose to register the measured weight, especially when they suspect of the over or underestimation of the reported one.

The systematic tendency of women overestimating height and underestimating weight results in the underestimation of BMI. Even though reported BMI values did not compromise about $90 \%$ of the classifications of nutritional status, and even though Kappa revealed an almost perfect concordance between them, in cases of bordering BMI values or more extreme discordances there are classification errors. Therefore, in prenatal follow-up or in other cases in which a nutritional conduct should be chosen based on obtained BMI, weight and height measurement is indispensable.

The results presented in this study point out some needs: the capacitation of professionals in the weight measurement process; their closer look to younger pregnant women with lower schooling; the periodical maintenance of equipment and the replacement of mechanical scales with electronic ones. Besides, due to the high concordance of anthropometric measurements reported by the pregnant women and registered in prenatal cards, it is worth to mention that pre-gestational and current weight and height information reported by the pregnant women can be used in studies, at the absence of registers in the cards, when the economy of these resources is important for the development of the study. However, it is important to improve these two sources of information by improving the conformity of the anthropometric process in health units.

\section{References}

1. Brasil. Ministério da Saúde. Pré-natal e Puerpério: atenção qualificada e humanizada - manual técnico. Brasília: Ministério da Saúde; 2006.

2. Heslehurst N, Simpson H, Ells LJ, Rankin J, Wilkinson J, Lang R, et al. The impact of maternal BMI status on pregnancy outcomes with immediate short-term obstetric resource implications: a meta-analysis. Obes Rev 2008; 9(6): 635-83.

3. Siega-Riz AM, Viswanathan M, Moos M-K, Deierlein A, Mumford S, Knaack J, et al. A systematic review of outcomes of maternal weight gain according to the Institute of Medicine recommendations: birthweight, fetal growth, and postpartum weight retention. Am J Obstet Gynecol 2009; 201(4): 339.e1-14.

4. Barros DC. SISVAN: Instrumento para o Combate aos Distúrbios Nutricionais na Atenção à Saúde - A
Antropometria. Rio de Janeiro: Centro Colaborador de Alimentação e Nutrição (CECAN) - Região Sudeste; 2005.

5. Donabedian A. The quality of care. How can it be assessed? 1988. Arch Pathol Lab Med 1997; 121(11): 1145-50.

6. Coutinho T, Teixeira MTB, Dain S, Sayd JD, Coutinho LM. Adequação do processo de assistência pré-natal entre usuárias do Sistema Único de Saúde em Juiz de Fora, MG. Rev Bras Ginecol Obstet 2003; 25(10): 717-24.

7. Niquini RP, Bittencourt SA, Lacerda EMA, Saunders C, Leal MC. Avaliação do processo da assistência nutricional no pré-natal em sete unidades de saúde da família do Município do Rio de Janeiro. Cienc Saude Colet 2012; 17(10): 2805-16.

8. Connor Gorber S, Tremblay M, Moher D, Gorber B. A comparison of direct vs. self-report measures for assessing height, weight and body mass index: a systematic review. Obes Rev 2007; 8(4): 307-26. 
9. Engstrom JL, Paterson SA, Doherty A, Trabulsi M, Speer KL. Accuracy of self-reported height and weight in women: an integrative review of the literature. J Midwifery Womens Health 2003; 48(5): 338-45.

10. Capelli JCS, Anjos LA, Castro IRR. Qualidade do valor da medida de massa corporal nos Centros Municipais de Saúde do Município do Rio de Janeiro, 1996. Cad Saude Publica 2002;18(1): 63-70.

11. Lima MA, Oliveira MA, Ferreira Hda S. Confiabilidade dos dados antropométricos obtidos em crianças atendidas na Rede Básica de Saúde de Alagoas. Rev Bras Epidemiol 2010; 13(1): 69-82.

12. Nucci LB, Duncan BB, Mengue SS, Branchtein L, Schmidt MI, Fleck ET. Assessment of weight gain during pregnancy in general prenatal care services in Brazil. Cad Saude Publica 2001; 17(6): 1367-74.

13. Brasil. Ministério da Saúde. Vigilância alimentar e nutricional - Sisvan: orientações básicas para a coleta, processamento, análise de dados e informação em serviços de saúde. Brasília: Ministério da Saúde; 2004.

14. Dubeux LS, de Frias PG, Vidal AS, Santos DM. Incentivo ao aleitamento materno: uma avaliação das equipes de saúde da família do município de Olinda, Pernambuco. Rev Bras Saude Matern Infant 2004; 4 (4): 399-404.

15. Bland JM, Altman DG. Statistical Methods for assessing agreement between two methods of clinical measurement. Lancet, 1986; 1(8476): 307-10.

16. Bland JM, Altman DG. Measuring agreement in method comparison studies. Stat Methods Med Res 1999; 8(2):135-60.

17. Fleiss JL. The design and analysis of clinical experiments. New York: John Wiley \& Sons; 1986.
18. WHO (World Health Organization). Physical status: the use and interpretation of anthropometry: report of a WHO Expert Committee. Geneva: WHO; 1995.

19. Atalah E, Castillo C, Castro R, Aldea A. Propuesta de un nuevo estándar de evaluación nutricional en embarazadas. Rev Med Chil 1997; 125(12): 1429-36.

20. Kac G, Nucci LB, Spyrides MH, Duncan BB, Schmidt MI. Evaluation of the ability of a Latin-American gestational weight curve to predict adverse pregnancy outcomes. Int J Gynaecol Obstet 2009; 106(3): 223-6.

21. Melo MIB, de Souza AI, Figueiroa JN, Cabral-Filho JE, Benício MHA, Batista-Filho M. Estado nutricional de gestantes avaliado por três diferentes métodos de classificação antropométrica. Rev Nutr Campinas 2011; 24(4): 585-92.

22. Landis JR, Koch GG. The measurement of observer agreement for categorical data. Biometrics, 1977; 33:159-74.

23. Oliveira AF, Gadelha AM, Leal MdoC, Szwarcwald CL. Estudo da validação das informações de peso e estatura em gestantes atendidas em maternidades municipais no Rio de Janeiro, Brasil. Cad Saude Publica 2004; 20 Sup 1: S92-S100.

24. Fonseca Mde J, Faerstein E, Chor D, Lopes CS. Validade de peso e estatura informados e índice de massa corporal: estudo pró-saúde. Rev Saude Publica 2004; 38(3): 392-8.

25. Chor D, Coutinho Eda S, Laurenti R. Reliability of self-reported weight and height among State bank employees. Rev Saude Publica 1999; 33(1): 16-23.

Received on: 03/30/12

Final version presented on: 10/19/12

Accepted on: 01/15/13 